\title{
Efficiency of Dissimilar Friction Welded SAF 2205 Duplex Stainless Steel and 1045 Medium Carbon Steel Joints
}

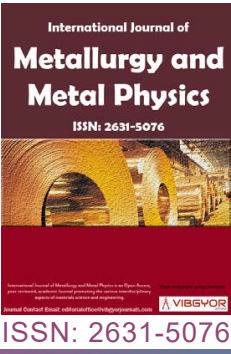

\section{Gawhar Ibraheem Khidhir}

Department of Mechanical and Mechatronics Engineering, Salahaddin University, Erbil, Iraq

\begin{abstract}
This study investigated the microstructure and mechanical properties of frictional welded joints between SAF 2205 duplex stainless steel and AISI 1045 medium carbon steel. The welded joints were fabricated by varying the friction pressure, friction time, and keeping the forging pressure, forging time and rotational speed as constant to obtain a constant range of welding temperature $\left(780-800^{\circ} \mathrm{C}\right)$. The results revealed that as the friction pressure increases and friction time decreases, weld interface hardness value, tensile strength and ductility increases. Also the hardness profiles present that weld interfaces exhibit higher hardness values than that of the two base metals. It was found that the highest efficiency of weld joint achieved was $93 \%$, while the lowest was $76 \%$. In addition, all welded specimens failed in the weld region. The microstructure analyses were carried out using optical microscopy and scanning electron microscopy equipped with energy dispersive spectroscopy.
\end{abstract}

\section{Keywords}

Friction welding, Mechanical properties, Microstructural characterization, 2205 DSS, 1045 MCS

\section{Introduction}

Duplex stainless steels (DSSs) are considered as a type of stainless steels, generally provided with approximately equal volume fraction of $\alpha$-ferrite phase and $\gamma$-austenite phase [1]. Consequently, microstructures of DSSs take advantages of each individual ferritic and austenitic stainless steel (ASS). Ferritic stainless steels (FSSs) possess high yield strength, while ASSs have high toughness [2], therefore, the proper alternative to ASSs and FSSs are low Ni DSSs [3]. Nowadays, DSS SAF 2205 may be considered as one of the most extensively DSSs used due to their high mechanical and corrosion resistance [4], it is widely used in oil, chemical, nuclear industries, structural applications and marine constructions. In industrial applications, there is a strong request for dissimilar joining, because of the reason for economic consideration $[3,5]$. Many problems occur when welding DSSs by fusion welding process because it destroys the desired duplex microstructure resulting in coarse, high amount of ferrite and intermetallic phases $(\sigma)$ precipitation, consequently mechanical properties of welded joints will be decreased. Therefore the suitable technique will be using solid state welding processes [6]. One of the most common and often used solid state welding processes is continuous drive friction welding (CDFW) in which coalescence is produced by generation heat at the contact surfaces and by pressure applied. This method has an advantage of

*Corresponding author: Gawhar Ibraheem Khidhir, Department of Mechanical and Mechatronics Engineering, Salahaddin University, Erbil, Iraq

Accepted: March 15, 2021; Published: March 17, 2021

Copyright: (C) 2021 Khidhir GI. This is an open-access article distributed under the terms of the Creative Commons Attribution License, which permits unrestricted use, distribution, and reproduction in any medium, provided the original author and source are credited.

Khidhir. Int J Metall Met Phys 2021, 6:065

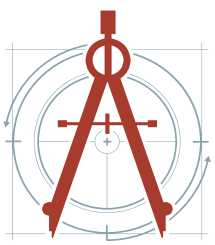


Table 1: Chemical compositions of base materials (wt. \%).

\begin{tabular}{|l|l|l|l|l|l|l|l|l|l|l|}
\hline Elements & $\mathbf{C}$ & $\mathbf{S i}$ & $\mathbf{M n}$ & $\mathbf{P}$ & $\mathbf{S}$ & $\mathbf{C r}$ & $\mathbf{M o}$ & $\mathbf{N i}$ & $\mathbf{N}$ & $\mathbf{F e}$ \\
\hline 2205(DSS) & 0.028 & 0.55 & 1.8 & 0.028 & 0.001 & 22.04 & 2.6 & 5.5 & 0.165 & Bal \\
\hline $\mathbf{1 0 4 5}$ (MCS) & 0.497 & 0.262 & 0.735 & 0.0124 & 0.0249 & 0.0428 & 0.0044 & 0.0156 & & Bal \\
\hline
\end{tabular}

Table 2: Mechanical properties of base materials.

\begin{tabular}{|l|l|l|l|l|l|}
\hline Material & Hardness(HV) & $\begin{array}{l}\text { Yield strength } \\
\text { (MPa) }\end{array}$ & $\begin{array}{l}\text { Ultimate tensile } \\
\text { strength (MPa) }\end{array}$ & $\begin{array}{l}\text { \% Elongation } \\
\mathbf{L}_{\mathbf{0}}=\mathbf{2 5} \mathbf{~ m m}\end{array}$ & \begin{tabular}{l} 
\% Reduction in area \\
\hline 2205(DSS)
\end{tabular} \\
\hline $\mathbf{1 0 4 5}$ (MCS) & 260 & 570 & 780 & 33 & 50 \\
\hline
\end{tabular}

low heat input, high material saving and low production time [7]. Many publications for friction welding (FW) of 2205 DSSs are available. Sarsilmaz, et al. [6] used CDFW between armor 500 and 2205 DSS and investigated the effect of friction pressure and friction time on the tensile properties. The study investigated that when the friction time was $8 \mathrm{~s}$ and friction pressure was $80 \mathrm{MPa}$, the highest tensile strength obtained, which is $1020 \mathrm{MPa}$, also concluded that an increase of frictional pressure and friction time lead to an increase in the tensile strength. Asif, et al. [7] used finite element model to predict the thermal history and axial shortening profiles by using ANSYS software tool. The experimental results used to validate the numerical model. Similarly Asif, et al. [8] studied the effect of heat input on mechanical properties and microstructures of 2205 DSS FW, different parameters were changed due to array with L9 orthogonal according to Design of Experiments. Tensile strength, toughness, micro hardness and corrosion behavior were evaluated, further in [9] the researchers found the effects of post weld heat treatment on 2205 DSSs weld. Ajith, et al. [10-13] jointed two bars of 2205 DSSs and evaluated the mechanical properties and microstructure, optimized and performed several experiment to evaluate joint characterization, while Mercan, et al. [14] optimized the welding parameters that affect increasing the fatigue strength of the joint between AISI 2205 and AISI 1020 bars. Caligulu, et al. [15-17] welded AISI 4340-2205 steels and studied the impact of rotation speed and friction time, use the $\mathrm{X}$-ray radiographic tests and found the weldability. Kirik, et al. [18] connected AISI 2205 to Ti6AI4V with and without nickel interlayer. However, many researches have been reported up to date on 2205 DSS jointed by FW as mentioned above; nevertheless, studies concerning dissimilar FW 2205 DSS and 1045 MCS is very scarce. The aim of this study is to investigate the effect of friction pressure on the efficiency of dissimilar friction welded SAF 2205 DSS-AISI 1045 MCS joints at a constant range of welding temperature. This type of FW, at a constant welding temperature can be used in applications that require considerable efficiency and strength; also, it coincides with the procedure of FW in real production processes.

\section{Experimental Procedures}

\section{Materials}

The base materials used in this study include cylindrical rods (16 mm diameter and $50 \mathrm{~mm}$ length) of SAF 2205 DSS and AISI 1045 MCS. The chemical compositions and mechanical properties of the materials used are given in Table 1 and Table 2 respectively.

\section{Welding process}

A lathe machine type (TSL, SER.No.NN94298) used for CDFW between 2205 DSS and 1045 MCS. The part of 2205 DSS was clamped on the stationary clamp of the tail stock, while 1045 MCS part was fixed on the rotating chuck. For reading the friction and forge pressures during the welding process a load cell was arranged on the side of the tail stock and a stopwatch was adjusted for reading friction and forging times. K-type thermocouple device model (ProsKiteMT-1280) was used during the application of friction pressure to measure the temperature of the welded zone. Friction pressure was applied for a specified time to reach the system a certain temperature, then a brake stopped the rotation and simultaneously the specified forging pressure was applied to compress the samples together. In this paper the following parameters were held constant: The forging pressure at $75 \mathrm{MPa}$, the forging time at 2 seconds and the rotational speed 
$560 \mathrm{rpm}$. Table 3 shows the friction pressure and friction time as the two varying parameters, to obtain a constant temperature range of 780 to $800^{\circ} \mathrm{C}$, and Figure 1 shows the welded samples.

\section{Microstructure analysis}

The microstructures of the welded joints were conducted by using a computerized METKAN IMM901 microscope. A scanning electron microscopy (SEM) model (TESCAN, MIRA 3) was used for observing the fractured surface in tensile test samples. The SEM was equipped with an energy

Table 3: Process parameters used.

\begin{tabular}{|l|l|l|}
\hline Sample No. & $\begin{array}{l}\text { Friction pressure } \\
\text { (MPa) }\end{array}$ & $\begin{array}{l}\text { Friction time } \\
\text { (sec) }\end{array}$ \\
\hline Sample (1) & 35 & 50 \\
\hline Sample (2) & 45 & 47 \\
\hline Sample (3) & 55 & 43 \\
\hline Sample (4) & 65 & 41 \\
\hline Sample (5) & 75 & 38 \\
\hline
\end{tabular}

dispersive spectroscopy (EDS). Then it was used for analyzing the chemical composition of the weld fracture after the tensile test. The specimens were prepared for microstructure analyses according to ASTM E3-11. Etching for 1045 MCS was done by (Nital). While aqua regia was used to reveal the microstructures of 2205 DSS specimen [19].

\section{Mechanical tests}

The mechanical properties were determined through the hardness and tensile tests. The hardness profile was taken across the weld centerline according to ASTM E92-03 [20]. Hardness measurement was carried out with a load of $50 \mathrm{~kg}$ for 15 seconds by a testing machine AKASHI type model AVA. Tensile test samples were prepared according to ASTM A370, with a gage length (G) of $25 \mathrm{~mm}$ and diameter (D) of 6.25 $\mathrm{mm}$. The weld interface was in the center of the gage length as shown in Figure 2. The samples were tested in tension by using Hualong type WAW 600. The joint efficiency $(\eta)$ was calculated in terms of the tensile strength of the welded metal divided by the tensile strength of softer metal as indicated in Equation (1).

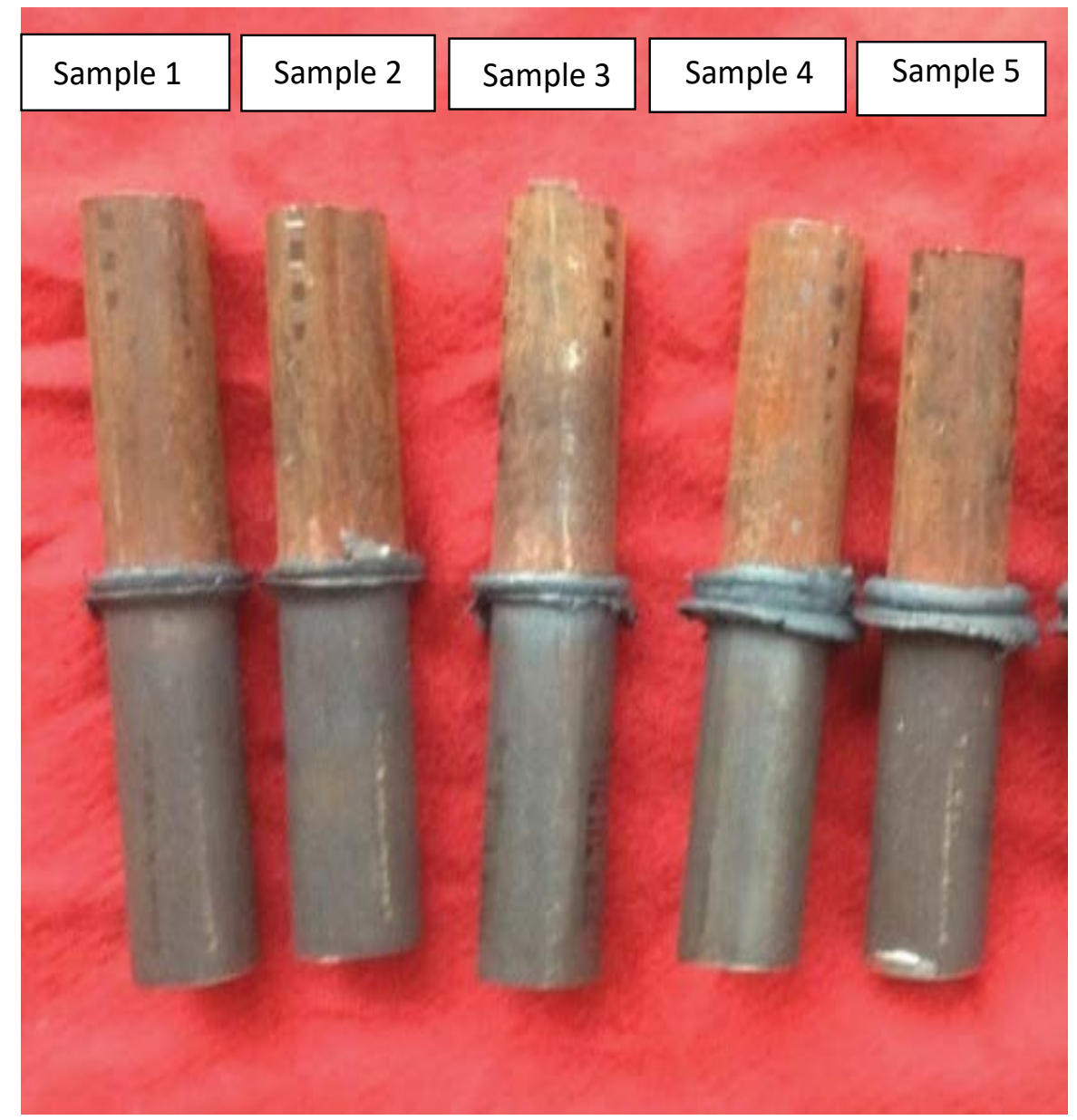

Figure 1: Welded samples. 
(a)



Figure 2: $(a, b)$ Measurement and shape of the tensile test specimens.
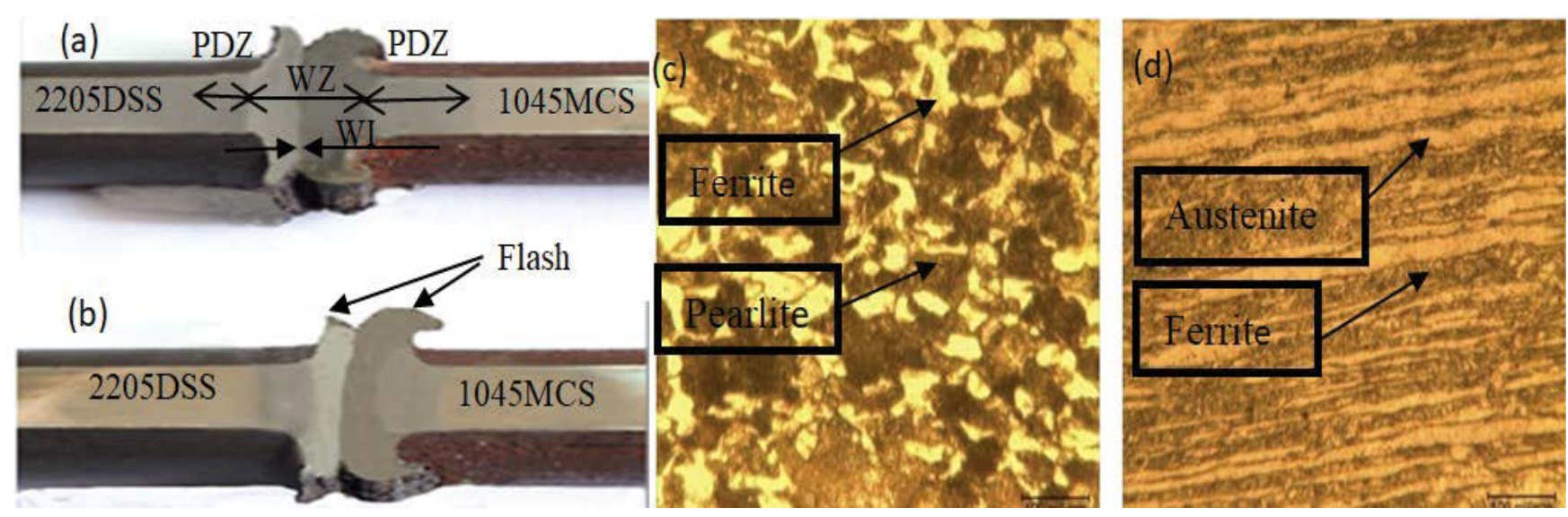

Figure 3: (a,b) Macrostructure of the welded sample (1) and Sample (5); (c) Microstructure of base 1045 (MCS); (d) Microstructure of base 2205 DSS.

$$
\text { Efficiency }(\eta)=\frac{\text { Tensile strength of weld jo int }}{\text { Tensile strength of softer metal(1045 MCS part) }} * 100 \% \ldots \ldots \ldots . . .
$$

\section{Results and Discussion}

\section{Visual examinations}

The visual observations revealed that there were no cracks and voids presented on the surface of the welded joints. That indicates the integrity of the joints. Also, for all cases, the flash forms in 1045 MCS side is greater than in the 2205 DSS side and it curls around the back towards the part, while the flash of DSS side is relatively straight from the joint Figure $3 a$ and Figure $3 b$. This is due to the higher thermal expansion and thermal conductivity of 1045 MCS compared to those in 2205 DSS. In addition, the presence of alloying elements especially $\mathrm{Cr}$ and the higher hardness of 2205 DSS than 1045 MCS at higher temperatures. This result is identical to FW between SAF 2507 and mild steel obtained by Gardi [21]. Moreover, the amount of flash increased with an increase in friction pressure, the same result obtained for FW between AISI 2205 and AISI 4340 in [16].

\section{Macrostructure and microstructure}

Macrographs of the welded Sample (1) and Sample (5) are displayed in Figure 3a and Figure 3b. It comprises of four distinct zones: Weld interface (WI), weld zone (WZ), partially deformed zone (PDZ), and base metal (BM) on both sides. The width of WZ and PDZ of 1045 MCS side is greater than that of 2205 DSS side, due to the difference in the coefficient of transmission heat for the two materials [14,21]. Further, their widths were greater in Sample (1) than in Sample (5), as in the case of Sample (1) the friction pressure is less with longer time. Longer time intervals promote greater propagation of thermal energy as a result, a bulk volume of material is heated which means a wider PDZ is obtained, and, as a consequence, lower mechanical properties is achieved. These characteristic zones in 2205 DSS side are discussed in detail in the microstructure field. The microstructure of 1045 MCS base metal is shown in Figure $3 \mathrm{c}$ which consists of ferrite (light) and perlite (dark) areas. The ferrites are uniformly distributed along the pearlite grain 
boundaries and have grain sizes of about $28 \mu \mathrm{m}$. Furthermore, Figure $3 \mathrm{~d}$ shows the microstructure of 2205 DSS which comprises of austenite islands (light) in a ferrite matrix (dark) in almost equal proportion, with grain sizes of approximately $27 \mu \mathrm{m}$, and the elongated austenite phases indicated the rolling direction. The chromium and nickel equivalents $\left(\mathrm{Cr}_{\text {eq, }}, \mathrm{Ni}_{\text {eq }}\right)$ are determined by Equations (2) and (3) according to Schaeffler diagram [22]; thus the $\mathrm{Cr}_{\text {eq }}$ for 2205 DSS base metal is 25.4 and $\mathrm{Ni}_{\text {eq }}$ is 7.24, therefore the $\mathrm{Cr}_{\text {eq }} / \mathrm{Ni}_{\text {eq }}$ value is 3.5.

$$
\begin{aligned}
& \mathrm{Cr} \text { eq }=\mathrm{Cr}+\mathrm{Mo}+1.5 * \mathrm{Si}+0.5 * \mathrm{Nb} \ldots \ldots \ldots \\
& \mathrm{Ni} \text { e } q=\mathrm{Ni}+30 * \mathrm{C}+0.5 * \mathrm{Mn} \ldots \ldots \ldots \ldots \ldots \ldots
\end{aligned}
$$

The microstructures from the welded joint to base metal 2205 DSS for Sample (1) are shown in Figure 4a, Figure $4 \mathrm{~b}$ and Figure $4 \mathrm{c}$. The microstructure of the interface is obvious because it is the line between 1045 MCS and 2205 DSS. Figure 4a shows the grain refinement due to dynamic recrystallisation along with the formation of fine carbide at WZ, which is attributed to the mutual effect of mechanical and thermal stresses that resulted in improvement in hardness properties and lowering tensile strength. This type of refinement is also discussed by [14]. Also WZ show higher volume of austenite phase when compared to ferrite phase. The deformed austenite grains are clear in WZ as in Figure 4b, whereas in Figure 4c, the austenite grains $(\gamma)$ in PDZ become coarser in ferrite matrix $(\alpha)$. Figure $4 d$, Figure $4 \mathrm{e}$ and Figure $4 \mathrm{f}$ shows the microstructure in Sample (5), which is completely equiaxed uniform grains of austenite and more refined grains occur without any carbide in the WZ due to increasing friction pressure which lead to dynamic recrystallization, because of more severer plastic deformation Moreover, ferrite volume increased as the dark region increased compared to sample (1), the same feature indicated by Caligulu [17] who stated that the higher the friction pressure, then the greater amount of viscous materials is extracted out of the interface.

\section{Mechanical properties}

Hardness tests: Figure 5 represents micro hardness variations on both sides of the interface at a distance of $1 \mathrm{~mm}$ apart; the average value for every three samples was calculated for each case. The hardness profiles were resembled in all samples. Weld zone hardness was higher than the hardness of the base metals, it may be associated to chemical composition and microstructure in weld interface


Figure 4: Microstructure of different regions on 2205 (DSS) side, sample (1): (a) WI and WZ; (b) WZ; and (c) PDZ. Sample (5); (d) WI and WZ; (e) WZ; and (f) PDZ. 


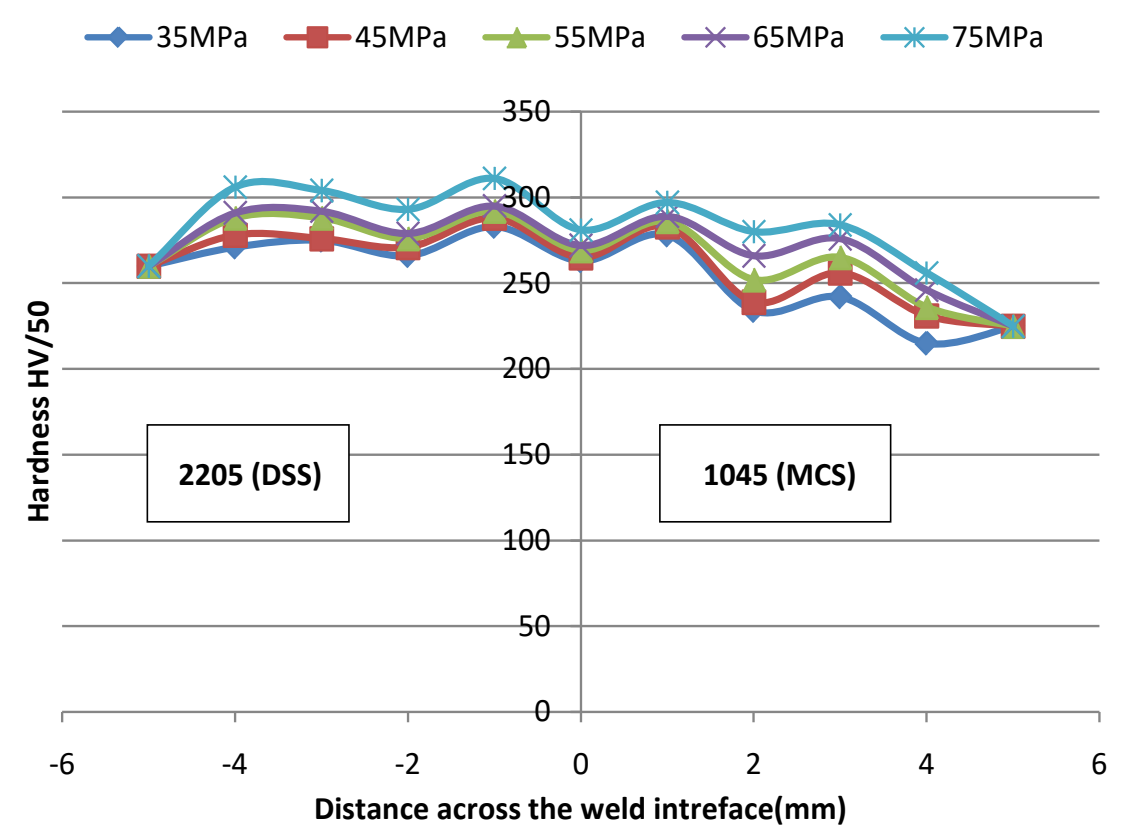

Figure 5: Vickers hardness distributions for welded joint.

$[5,9]$. The distribution of hardness slightly changes for the different regions. Moreover, It has been observed that the hardness of the welding interface for all samples exhibit lower value than of the area close to it for both sides. This may be attributed to the refinement of grains occurred close to weld interface and higher amount of ferrite phase $[11,13]$. Beyond that, in all samples the hardness is fluctuated and then goes toward the hardness of base metals. In general, the hardness in 2205 DSS side gives higher hardness than 1045 side due to the differences in the transmission of heat among the materials. Furthermore, It can be noticed that at constant forging pressure, as friction pressure increased and at constant range of temperature, the plastic deformation increased and the hardness value in $\mathrm{WI}$ increased for all samples, the hardness value increased from $263 \mathrm{HV}$ for $35 \mathrm{MPa}$ to $281 \mathrm{HV}$ for $75 \mathrm{MPa}$ at constant forging pressure $75 \mathrm{MPa}$ which is due to grain refinement occurring as previously indicted in Figure $4 d$ due to increasing of plastic deformation. These results agreed with the features obtained in [14].

Tensile properties: Tensile test results are presented in Figure $6 \mathrm{a}$ and Figure $6 \mathrm{~b}$ which reveals the ultimate tensile strength, elongation $\%$ and efficiency of the joint \%, three samples were tested for each case and average of them was taken in the figure. From Figure 6 a note that the ultimate tensile strength value of the welded samples is less than that of the parent materials, or $750 \mathrm{MPa}$ for 1045 MCS and $780 \mathrm{MPa}$ for 2205 DSS. Further, the ultimate tensile strength value of the welded specimen increases as the friction pressure increased and friction time decreased. For instance, the minimum tensile strength belonged to the Sample (1) being $572 \mathrm{MPa}$, while the maximum tensile strength is obtained for Sample (5) being $698 \mathrm{MPa}$, because at constant range of temperatures, with low friction pressure and high friction time, the more diffusion and microstructure degradation occurs, due to precipitation of more chromium carbide and formation of brittle intermetallic phases, which affect decreasing of bond strength, while by increasing friction pressure and decreasing friction time, finer grains produced, carbides don't appear and lead to higher tensile strength. This result conforms to microstructure in Figure $4 \mathrm{a}$ and Figure $4 \mathrm{~d}$. Also, from Figure $6 \mathrm{~b}$ observed that the efficiency is increased from $76 \%$ to $93 \%$ as the friction pressure increased from $35 \mathrm{MPa}$ to $75 \mathrm{MPa}$. This indicates that lower friction pressure lead to insufficient plastic deformation at the interim surfaces and the optimum efficiency of the joint could be obtained by the increasing friction pressure. This result quite agreed with researches $[14,17]$. As the friction time is high, the ductility is reduced in Sample (1) because the inclusions may affect welding region due to low friction pressure, while at low friction time and high friction pressure these inclusions extracts out from weld region as its clear in Table 4, therefore 


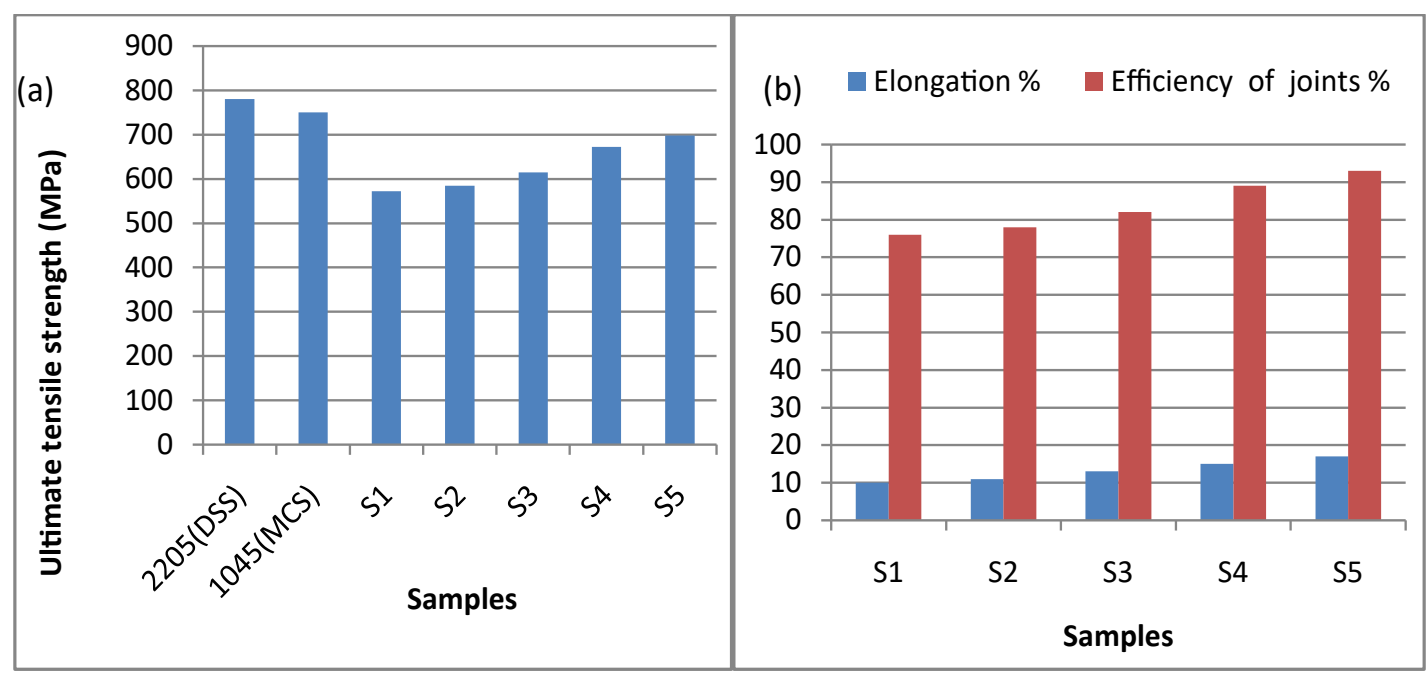

Figure 6: (a) Ultimate tensile strength; (b) Elongation \% and efficiency of joints \%.

Table 4: Chemical composition detected by EDS analysis for Sample (1) and Sample (5).

\begin{tabular}{|l|l|l|l|l|}
\hline & \multicolumn{2}{|l|}{ Sample(1) } & \multicolumn{2}{l|}{ Sample(5) } \\
\hline Element & Wt.\% & A\% & Wt.\% & A\% \\
\hline C & 1.9 & 7.21 & 1.03 & 4.37 \\
\hline Si & 4.68 & 7.6 & 4.21 & 7.63 \\
\hline Cr & 30.7 & 26.91 & 23.89 & 23.39 \\
\hline Fe & 51.82 & 42.31 & 70.6 & 64.37 \\
\hline Ni & 0.91 & 0.71 & 0.27 & 0.23 \\
\hline Al & 3.93 & 6.64 & - & - \\
\hline S & 6.06 & 8.62 & - & - \\
\hline & 100.00 & 100.00 & 100.00 & 100.00 \\
\hline
\end{tabular}

ductility increased from $10 \%$ for sample (1) to $17 \%$ for sample (5). All of the samples are fractured in weld interface. This is attributed to chemical in-homogeneity and microstructural changes.

Sample (1) shows brittle characteristics of the fracture appearance, while cup and cone fracture observed in sample (5) as shown in Figure 7a and Figure 7b. This approved by SEM photos examination on fracture samples, where Sample (1) exhibit quasi-cleavage mode, shown in Figure 7c, mean dimple with flat surface. While Sample (5) shows ductile mode fractures Figure $7 d$, this mode consists of spherical dimples region. This is well agreeing with tensile results discussed previously.

The diffusion process is further supported by EDS results in Figure 8a, Figure 8b, and Table 4, which represent quantitative results for major element content in (wt. \%) for Sample (1) and Sam- ple (5). Sample (1) involves low friction pressure and more friction time, mean more element diffusion. Therefore, present more carbon, chromium, and nickel content, also aluminum and sulphur exists, while Sample (5) exhibit high friction and less time for diffusion, therefore, the amount of $\mathrm{C}, \mathrm{Cr}$, $\mathrm{Ni}$ decreases. From the EDS results, the chromium and nickel equivalents are determined using Equations (2) and (3) respectively. For Sample (1): $\mathrm{Cr}_{\text {eq }}$ is 37.72 and $\mathrm{Ni}_{\text {eq }}$ is 57.91, while for Sample (5): $\mathrm{Cr}_{\text {eq }}$ is 30.2 and $\mathrm{Ni}_{\text {eq }}$ is 31.17. The results of $\mathrm{Cr}_{\text {eq }} / \mathrm{Ni}_{\text {eq }}$ indicated that the weld zone of Sample (5) have nearly 1:1 ratio of ferrite and austenite phase stabilizing alloying elements amount and present a more balanced microstructure.

\section{Conclusions}

This paper evaluates the impact of friction pressure on microstructure analysis and mechanical properties of dissimilar metals joint SAF 2205DSS and AISI 1045 connected by CDFW and the conclusions are listed as follows:

1) FW process is successfully carried out to joint SAF 2205 DSS and 1045 MCS in a constant range of welding temperatures $\left(780-800{ }^{\circ} \mathrm{C}\right)$, with a maximum efficiency of $93 \%$, that was achieved with a friction pressure $75 \mathrm{MPa}$ and friction time of 38 seconds.

2) The microstructure reveals that the widths of WZ and PDZ of 1045 MCS side were greater than those of 2205 DSS side and the width of them also decreases with increasing the friction pressure. 

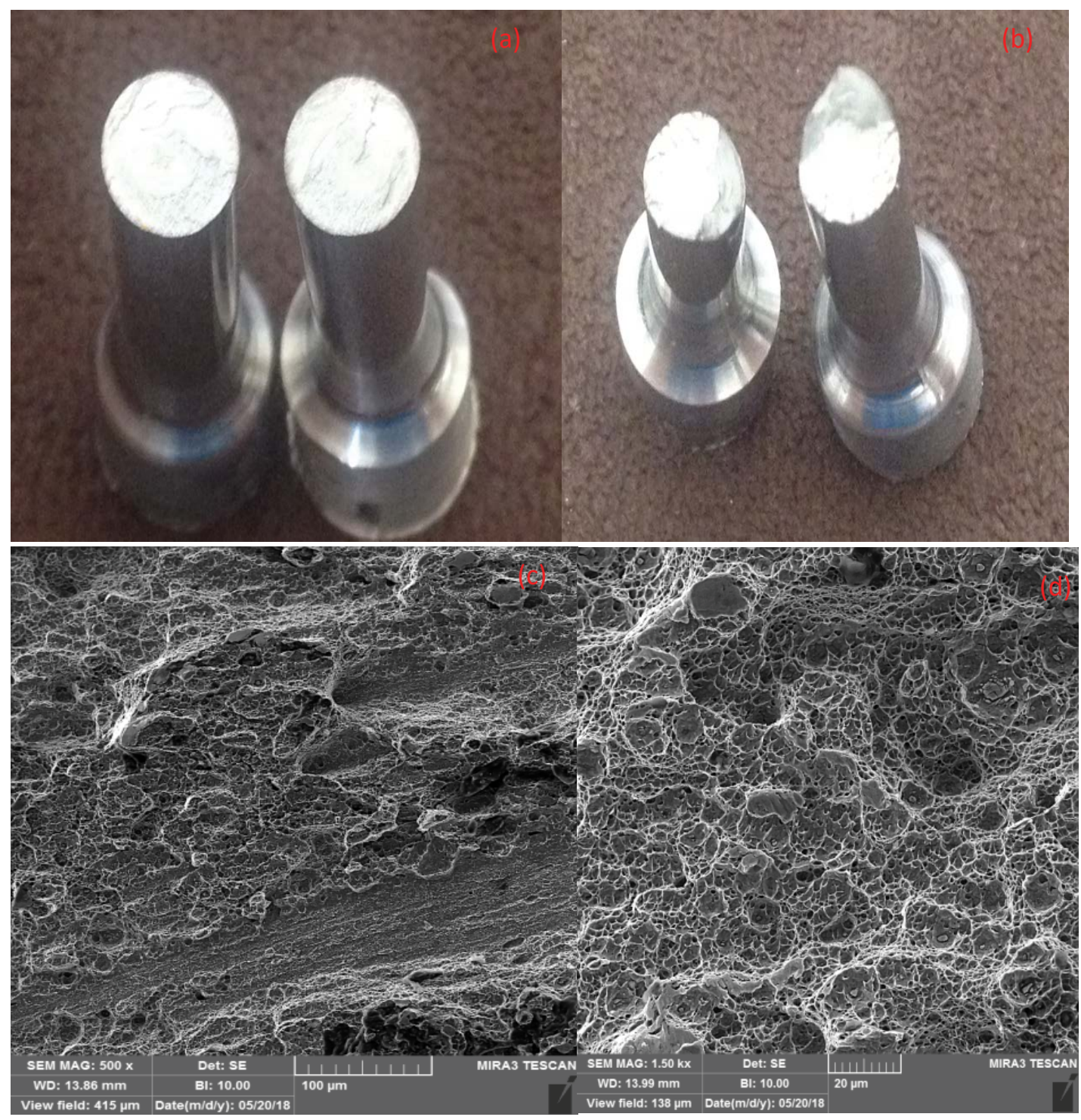

Figure 7: Fracture appearance and SEM morphology after tensile test: (a) for Sample (1); (b) For Sample (5); (c) SEM for Sample (1); (d) SEM for Sample (5).
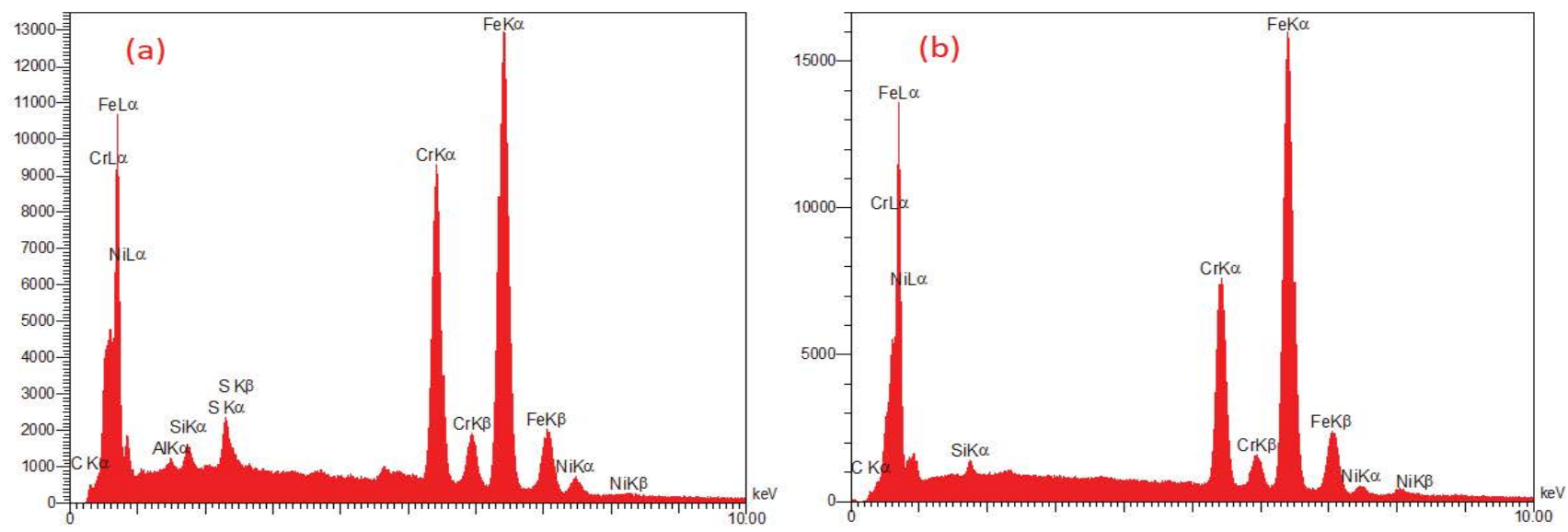

Figure 8: EDS analysis: (a) For Sample (1); (b) For Sample (5). 
3) Microhardness values at the interface increases with increasing friction pressure and decreasing friction time.

4) Tensile strength and ductility are found to increase with an increase in friction pressure and fracture occurring in the weld interface. The SEM photos show a quasi-cleavage fracture appearance in Sample (1) and a ductile fracture in Sample (5). This result was confirmed by the EDS test.

5) Schafler diagram for welded interface indicates that $\mathrm{Cr}_{\mathrm{eq}} / \mathrm{Ni}_{\mathrm{eq}}$ ratio has a decisive influence on the microstructure. Equal ratio of ferrite - austenite stabilizer for sample (5) gives more microstructure balance close to the initial microstructure of the parent alloy.

\section{Conflicts of Interest}

There is no conflict of interest to declare.

\section{Funding}

This study is funded and sponsored by Salahaddin University-Erbil.

\section{Acknowledgements}

The author would like to thank Mechanical and Mechatronics department in the College of Engineering at Salahaddin University for facilitating this research, also would like to thank Mr. Sardar A. for his help in performing the SEM and EDS test.

\section{References}

1. Tao $P$, Gong J Ming, Wang Y Fei, Jiang Y, Li Y, et al. (2018) Characterization on stress-strain behavior of ferrite and austenite in a 2205 duplex stainless steel based on nanoindentation and finite element method. Results Phys 11: 377-384.

2. Rafael G, Pereiraa VF, Maysa T, Eduardo B, Ricardo R, et al. (2019) Microstructure and mechanical properties offriction stir welded $8 \mathrm{~mm}$ pipe SAF 2507 superduplex stainless steel. Journal of Materials Research and Technology 8: 243-249.

3. Emami S, Saeid T, Khosroshahi RA (2017) Microstructural evolution of friction stir welded SAF 2205 duplex stainless steel. J Alloys Compd 739: 678-689.

4. Lai R, Cai Y, Wu Y, Li F, Hua X (2016) Influence of absorbed nitrogen on microstructure and corrosion resistance of 2205 duplex stainless steel joint processed by fiber laser welding. J Mater Process Technol 231: 397-405.
5. Moteshakker A, Danaee I, Moeinifar S, Ashrafi A (2015) Hardness and tensile properties of dissimilar welds joints between SAF 2205 and AISI 316L. Sci Technol Weld Join 21: 1-10.

6. Sarsilmaz F, Kirik I, Bat S (2017) Microstructure and mechanical properties of armor 500/AISI2205 steel joint by friction welding. J Manuf Process 28: 131-136.

7. Asif MM, Shrikrishana KA, Sathiya P (2015) Finite element modelling and characterization of friction welding on UNS S31803 duplex stainless steel joints. Eng Sci Technol an Int J 18: 704-712.

8. Asif MM, Shrikrishna KA, Sathiya P, Goel S (2015) The impact of heat input on the strength, toughness, microhardness, microstructure and corrosion aspects of friction welded duplex stainless steel joints. J Manuf Process 18: 92-106.

9. Asif MM, Shrikrishna KA, Sathiya P (2016) Effects of post weld heat treatment on friction welded duplex stainless steel joints. J Manuf Process 21: 196-200.

10.Ajith PM, Sathiya P, Aravindan S (2014) Characterization of microstructure, toughness, and chemical composition of friction-welded joints of UNS S32205 duplex stainless steel. Friction 2: 82-91.

11.Ajith PM, Barik BK, Sathiya P, Aravindan S (2015) Multiobjective optimization of friction welding of UNS S32205 duplex stainless steel. Def Technol 11: 157-165.

12. Ajith PM, Husain TM, Sathiya P, Aravindan S (2015) Multi-objective optimization of continuous drive friction welding process parameters using response surface methodology with intelligent optimization algorithm. J Iron Steel Res Int 22: 954-960.

13. Ajith PM, Sathiya P, Aravindan S (2014) Experimental investigation on friction welding of UNS S32205 duplex stainless steel. Acta Met 27: 995-1007.

14. Mercan S, Aydin S, Özdemir N (2015) Effect of welding parameters on the fatigue properties of dissimilar AISI 2205-AISI 1020 joined by friction welding. Int J Fatigue 81: 78-90.

15.Caligulu U, Yalcinoz M, Kati N, Balalan Z, Islak S (2015) The effects of rotation speed and friction time for joining of AISI 4340-2205 steels by friction welding. Metallofiz Noveishie Tekhnologii 37: 665-681.

16. Caligulu U, Yalcinoz M, Turkmen M, Mercan S (2016) X-ray radiography of aisi 4340-2205 steels welded by friction welding. Mater Tehnol 50: 39-45.

17.Caligulu U, Yalcinoz M (2015) The weldability of AISI 4340-AISI 2205 steels using friction welding. Optoelectron Adv Mater Rapid Commun 9: 1064-1071. 
18. Kirik I (2016) Weldability of Ti6AI4V to AISI 2205 with a nickel interlayer using friction welding. Mater Tehnol 50: 353-356.

19.Voort GF Vander (2004) Metallography and microstructures. ASM International, 9.

20.Howard Kuhn DM (2000) Mechanical testing and evaluation. ASM International, 8.
21.Gardi RH, Kako SA (2012) Efficiency of dissimilar friction welded (Super duplex stainless steel SAF 2507mild steel) joints. Al-Rafidain Eng 21: 56-65.

22.Lamet (1993) Welding brazing and soldering. ASM Handbook, 6. 